\title{
Analysis and Design of a Single-Phase Tapped-Coupled-Inductor Boost DC-DC Converter
}

\author{
Michael Njoroge Gitau ${ }^{*}$, Fredrick Mukundi Mwaniki ${ }^{\dagger}$, and Ivan W. Hofsajer ${ }^{* *}$ \\ $\dagger^{*}$ Dept. of Electrical, Electronic and Computer Eng., University of Pretoria, Pretoria, South Africa \\ ${ }^{* *}$ School of Electrical and Information Eng., University of Witwatersrand, Johannesburg, South Africa
}

\begin{abstract}
A single-phase tapped-inductor boost converter has been proposed previously. However, detailed characterization and performance analysis were not conducted. This paper presents a detailed characterization, performance analysis, and design expressions of a single-phase tapped-coupled-inductor boost converter. Expressions are derived for average and RMS input current as well as for RMS input and output capacitor current ripple. A systematic approach for sizing the tapped-coupled inductor, active switch, and output diode is presented; such approach has not been reported in related literature. This study reveals that sizing of the inductor has to be based on current ripple requirement, turns ratio, and load. Conditions that produce discontinuous inductor current are also discussed. Analysis of a non-ideal converter operating in continuous conduction mode is also conducted. The expression for the voltage ratio considering the coupling coefficient is derived. The suitability of the converter for high-voltage step-up applications is evaluated. Factors that affect the voltage boost ratio are also identified.

The effects of duty ratio and load variation on the performance of the converter are also investigated. The theoretically derived characteristics are validated through simulations. Experimental results obtained at a low power level are included to validate the analytical and simulation results. A good agreement is observed among the analytical, simulation, and experimental results.
\end{abstract}

Key words: Battery, Bidirectional, Isolated, Modeling, Startup, Supercapacitor

\section{INTRODUCTION}

Many applications demand the use of a DC-DC converter with high voltage gain. Full utilization of renewable sources requires a converting stage to match the demanded voltage for effective grid connection. The start-up voltage for high-intensity discharge lamp ballasts utilized in automotive headlamps is as high as $400 \mathrm{~V}$. During steady-state operation, a DC-DC converter has to boost the $12 \mathrm{~V}$ of battery voltage to $100 \mathrm{~V}$ [1]. Electric and hybrid electric vehicles require high-voltage DC bus voltage from energy storage elements such as fuel cells, batteries, and ultracapacitors [2]. The $48 \mathrm{~V}$ nominal telecom DC bus voltage should be boosted to the intermediate $380 \mathrm{~V}$ DC bus voltage with the convergence of computer and telecommunication industries. Theoretically, conventional boost converters can achieve high step-up

\footnotetext{
Manuscript received Jan. 25, 2013; revised May 19, 2013

Recommended for publication by Associate Editor Honnyong Cha.

${ }^{\dagger}$ Corresponding Author: fredmukundi@gmail.com

Tel: +27-12-420-3111, University of Pretoria

*Dept. of Electrical, Electronic and Computer Eng., University of Pretoria, South Africa

** School of Electrical and Information Eng., University of Witwatersrand, South Africa
}

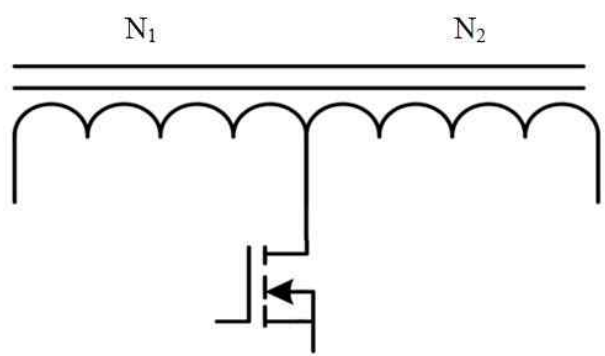

Fig. 1. Tapped-coupled inductors.

voltage gain at heavy-duty load conditions. However, voltage gain is limited in practice because of losses generated in the inductor, filter capacitor, active switch, and output diode. Given these losses, high voltage gain in a conventional boost converter can only be achieved with an extreme duty ratio. The output diode conducts for only a short time during each switching cycle with a high duty ratio, thereby resulting in serious reverse-recovery problems and an increase in the rating of devices [3].

Tapped inductors provide high step-up and step-down ratios with good efficiency without the need for isolation [4-14]. The two windings, $\mathrm{N}_{1}$ and $\mathrm{N}_{2}$, of the tapped inductor are on the same core and are therefore magnetically coupled as 
shown in Fig. 1. Large step-up conversion can be achieved by selecting the turn ratio of the tapped-inductor windings. Tapping the inductor is beneficial because it optimizes the duty cycle of the converter to achieve maximum efficiency. Tapping the inductor also allows a different mix of voltage and current ratings for various components in the converter [4].

The matrix of tapped inductor configurations is discussed in [4] and [5], including:

a) Switch-to-tap, where the switch is connected to the tapping point of the inductor rather than to one of the extremities of the inductor;

b) Diode-to-tap, where the diode is connected to the tapping point of the inductor rather than to one of the extremities of the inductor; and

c) Rail-to-tap, where the tap is connected to one of the power rails.

High-step-down converters that utilize a tapped inductor were investigated in [6] and [7]. Recent studies also indicate that a tapped inductor can be applied in high-step-up converters $[8,9,10]$. One of the limitations of a tapped-coupled inductor is leakage inductance, which results in a high-voltage spike across the switch during turn-off. This limitation requires the converter to employ a high-voltage switch to sustain variations and protect the switch or a snubber circuit to deplete the leakage energy. Although a single-phase tapped-coupled boost converter has been proposed previously, comprehensive design analysis has not been performed.

This paper presents a detailed characterization and the design expressions of a single-phase tapped-coupled-inductor boost converter, thereby addressing gaps in the literature. The operation of a non-ideal tapped-coupled-inductor boost converter in continuous conduction mode (CCM) is investigated. Expressions for the voltage boost ratio as well as factors that affect the boost ratio are presented. The effect of the coupling coefficient on performance is determined. Converter waveforms in CCM are presented, and analytical expressions for input average, RMS, and ripple current as well as for output capacitor RMS current are derived. The derived input and output side characteristics of the boost converter are validated through simulations. The conditions that produce discontinuous inductor current, the expressions required in sizing the coupled inductor, and the selection of the active switch and output diode are presented. This study reveals that given the nature of the converter's inductor current waveform, sizing of the inductor should be based on other considerations and not only on ripple minimization as described in the literature.

\section{OPERATION OF THE SINGLE-PHASE TAPPED-COUPLED-INDUCTOR BOOST CONVERTER}

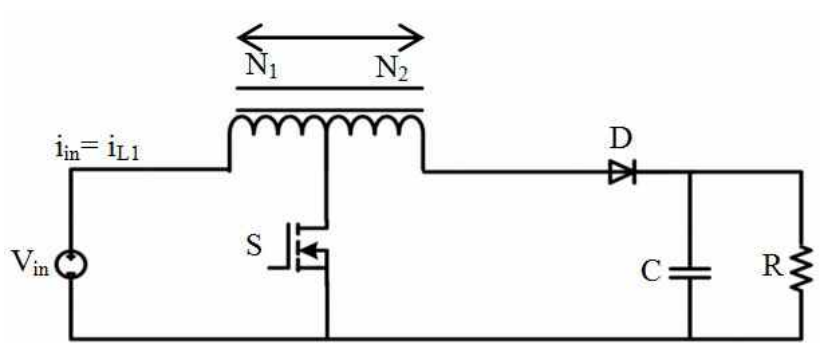

Fig. 2. Single-phase tapped-coupled-inductor boost converter.

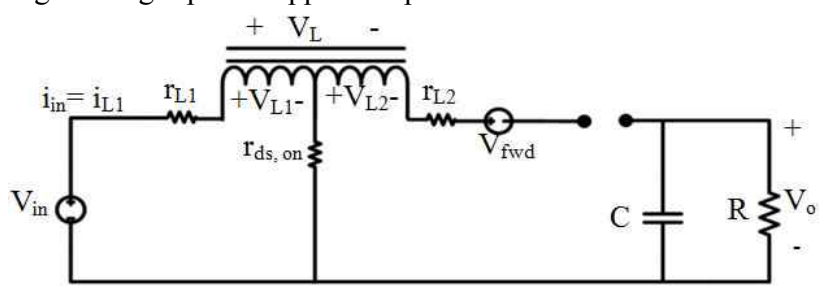

Fig. 3. Non-ideal tapped-coupled-inductor boost converter when the active switch is conducting.

A tapped-coupled-inductor boost converter is shown in Fig. 2. The circuit components include MOSFET S, diode D, tapped-coupled inductors $\mathrm{L}_{1}$ and $\mathrm{L}_{2}$, filter capacitor $\mathrm{C}$, and load resistance $\mathrm{R}$. The MOSFET is turned on by pulse-width modulator output through a gate drive circuit at duty ratio $=\frac{t_{\text {on }}}{t_{\text {on }}+t_{\text {off }}}$, where $\mathrm{t}_{\mathrm{on}}$ is the time when the MOSFET is conducting and $t_{\text {off }}$ is the time when the MOSFET is not conducting.

The windings $N_{I}$ and $N_{2}$ are on the same core and are therefore magnetically coupled. When $N_{2}=0$, the configuration reduces to that of a conventional boost converter. The relationship between $L_{1}$ and $L_{2}$ is determined by the turns ratio of the magnetic element, that is, $\frac{L_{2}}{L_{1}}=\left(\frac{N_{2}}{N_{1}}\right)^{2}=n^{2} . \mathrm{N}_{1}$ is the number of turns in the first inductor, and $\mathrm{L}_{1}$, and $\mathrm{N}_{2}$ are the number of turns in the second inductor, $\mathrm{L}_{2}$. The converter operates in two states when the switch is on and off in CCM.

Fig. 3 shows the equivalent converter circuit during the interval when the switch is conducting. $r_{\mathrm{L} 1}$ and $r_{\mathrm{L} 2}$ are the coupled-inductor winding resistances. During this interval, output diode $\mathrm{D}$ is reverse biased. Thus, input voltage $\mathrm{V}_{\text {in }}$ is described as

$$
\begin{gathered}
V_{\dot{\boldsymbol{n}}}=V_{L 1}+i_{L 1} r_{L 1}+i_{L 1} r_{d s, o n} \\
\therefore V_{L 1}=L_{1} \frac{d i_{L 1}}{d t}=\left(V_{\dot{\boldsymbol{n}}}-i_{L 1} r_{d s, o n}-i_{L 1} r_{L 1}\right)
\end{gathered}
$$

where $r_{d s, o n}$ is the channel resistance when the MOSFET is conducting. No current flows through the second inductor during this interval.

However, voltage $V_{L 2}$ appears across the second inductor because of the coupling. This voltage is obtained as

$$
V_{L 2}=M \frac{d i_{L 1}}{d t}=n k L_{1} \frac{d i_{L 1}}{d t}=n k V_{L 1}=n k\left(V_{\dot{\boldsymbol{n}}}-i_{L 1} r_{d s, o n}-\right.
$$




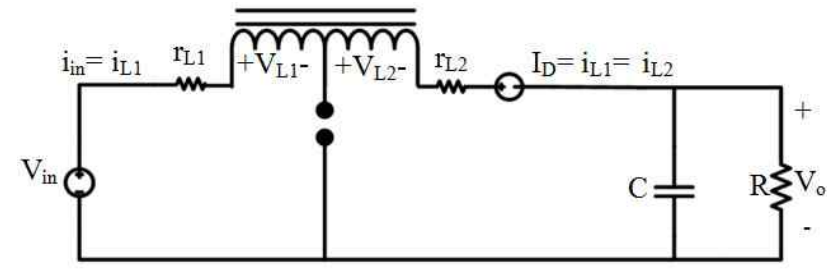

Fig. 4. Tapped-coupled-inductor boost converter with the output diode conducting.

where $M=n k L_{1}$ is the mutual inductance and $k$ is the coupling coefficient.

The total voltage across the two tapped-coupled inductors during this interval $\left(\mathrm{V}_{\mathrm{L}}\right)$ is therefore provided by

$$
\begin{gathered}
V_{L}=V_{L 1}+V_{L 2}=(1+n k) V_{L 1} \\
V_{L, \text { on }}=(1+n k) \times\left(V_{\text {in }}-i_{L 1} r_{d s, o n}-i_{L 1} r_{L 1}\right)
\end{gathered}
$$

where $V_{L, o n}$ is the tapped-coupled-inductor voltage when the switch is conducting. The expression for capacitor current is obtained as

$$
i_{c}=C \frac{d V_{o}}{d t}=-\frac{V_{o}}{R} .
$$

The input current during this interval is provided by

$$
i_{\text {n }}=i_{L 1} \text {. }
$$

Fig. 4 shows the converter during the interval when the diode is conducting. During this interval, the same current, iL, flows through both inductors. The voltage across the tapped-coupled inductors includes the voltage caused by mutual inductance between the two inductors.

The expressions for voltage across each of the inductors are

$$
V_{L 1}=L_{1} \frac{d i_{L}}{d t}+M \frac{d i_{L}}{d t} \Rightarrow\left(L_{1}+M\right) \frac{d i_{L}}{d t}
$$

and

$$
V_{L 2}=L_{2} \frac{d i_{L}}{d t}+M \frac{d i_{L}}{d t} \Rightarrow\left(L_{2}+M\right) \frac{d i_{L}}{d t}
$$

Given that the same current flows through both inductors during this interval, the rate of change $\frac{d i_{L}}{d t}$ is also equal. Thus,

$$
\begin{aligned}
& \frac{V_{L 1}}{L_{1}+n k L_{1}}=\frac{V_{L 2}}{n^{2} L_{1}+n k L_{1}} \\
& V_{L 2}=\left(\frac{n^{2}+n k}{1+n k}\right) \times V_{L 1} .
\end{aligned}
$$

As shown in Fig. 4, input and output voltage can be related to the inductor voltage as

$$
\left(V_{i n}-V_{o}\right)=V_{L 1}+V_{L 2}+i_{L}\left(r_{L 1}+r_{L 2}\right)+V_{f w d}
$$

where $\mathrm{V}_{\text {fwd }}$ is the diode forward voltage drop.

Substituting Equation (10) into Equation (12) yields an expression for the tapped-coupled-inductor voltage when the switch is off.

$$
\left(V_{\dot{\boldsymbol{n}}}-V_{o}\right)=V_{L 1}+\left\{\left(\frac{n^{2}+n k}{1+n k}\right) \times V_{L 1}\right\}+i_{L}\left(r_{L 1}+r_{L 2}\right)+V_{f w d}
$$

$$
\begin{gathered}
\Rightarrow V_{L, o f f}=\left\{V_{\dot{n}}-V_{o}-V_{f w d}-i_{L}\left(r_{L 1}+r_{L 2}\right)\right\}= \\
V_{L 1}\left\{\frac{n^{2}+2 n k+1}{1+n k}\right\}
\end{gathered}
$$

Referring to Fig. 4, $V_{L 1}=\left(\frac{N_{1}}{N_{1}+N_{2}}\right) \times V_{L, \text { off }}=\left(\frac{1}{1+n}\right) \times$ $\left\{V_{\boldsymbol{i}}-V_{o}-V_{f w d}-i_{L}\left(r_{L 1}+r_{L 2}\right)\right\} \quad$ and

$V_{L 2}=\left(\frac{N_{2}}{N_{1}+N_{2}}\right) \times V_{L, o f f}=\left(\frac{n}{1+n}\right) \times\left\{V_{\dot{n}}-V_{o}-V_{f w d}-\right.$ $\left.i_{L}\left(r_{L 1}+r_{L 2}\right)\right\}$.

The expression for the current through the output capacitor during this interval is

$$
i_{c}=C \frac{d V_{o}}{d t}=i_{L}-\frac{V_{o}}{R} .
$$

The input current during this interval is

$$
i_{\text {in }}=i_{L}=i_{L 1} \text {. }
$$

Equations (4) and (13) are averaged for the two time intervals with duty ratio as a weight to obtain one voltage equation applicable to one switching period.

$$
\begin{aligned}
& V_{L}=L \frac{d i_{L}}{d t}=\left[D \times\left\{(1+n k) \times\left(V_{\dot{\boldsymbol{n}}}-i_{L 1} r_{d s, o n}-\right.\right.\right. \\
& \left.\left.\left.i_{L 1} r_{L 1}\right)\right\}\right]+\left[(1-D) \times\left\{V_{\boldsymbol{n}}-V_{o}-V_{f w d}-i_{L}\left(r_{L 1}+\right.\right.\right. \\
& \left.\left.\left.r_{L 2}\right)\right\}\right] \\
& \quad V_{o}= \\
& \frac{1}{(1-D)}\left\{V_{\dot{n}}(1+n k D)+V_{f w d}(D-1)-D i_{L 1} r_{d s, o n}(1+\right. \\
& \left.n k)-D n i_{L} r_{L 1}(1+k(1+n))-i_{L}\left(r_{L 1}+r_{L 2}\right)\right\}
\end{aligned}
$$

The ripple through the capacitor in one switching period is

$$
i_{c}=C \frac{d v_{c}}{d t}=\left[D \times\left(-\frac{V_{o}}{R}\right)\right]+\left[(1-D) \times\left(i_{L}-\frac{V_{o}}{R}\right)\right]
$$

The average input current in one switching period is

$$
I_{\text {in }, \text { ave }}=I_{L 1}(n k D+1) \text {. }
$$

Based on Equation (18), the voltage transfer ratio (ignoring the non-ideal terms) is obtained as

$$
\frac{V_{o}}{V_{\dot{n}}}=\frac{1+n k D}{1-D} \text {. }
$$

A high boost ratio is obtained with a high coupling coefficient in the tapped-coupled boost converter from Equations (18) and (21). A low value of $k$ indicates high leakage inductance, which results in high voltage spikes across the switch during turn-off. This condition results in efficiency degradation because of the increased switching losses.

Equation (21) shows that the voltage transfer ratio of the tapped-coupled boost converter depends on the duty ratio, turns ratio, and coupling coefficient. When $n$ is equal to zero, the tapped-coupled boost converter is reduced to a conventional boost converter, which has a voltage gain of $\frac{V_{O}}{V_{\dot{n}}}=\frac{1}{1-D}$. 


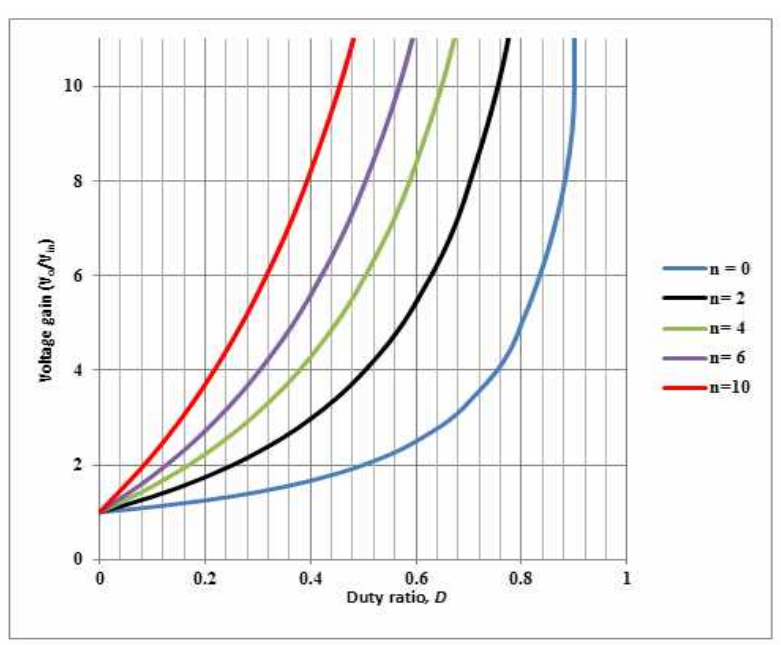

Fig. 5. Voltage gain against duty ratio D.

Rearranging Equation (21) yields the expression for duty ratio.

$$
D=\frac{\left(V_{0} / V_{\dot{i}}-1\right)}{\left(V_{0} / V_{\dot{m}}+n k\right)}
$$

Equation (22) indicates that as $n$ increases for a given voltage gain $\left(\mathrm{V}_{\mathrm{o}} / \mathrm{V}_{\text {in }}\right)$, a non-linear decrease occurs in $D$.

Fig. 5 illustrates the relationship among voltage gain, duty ratio $D$, and turns ratio $n$ for a coupling coefficient $k$ of 0.98 . The conventional boost converter with $n=0$ requires an extremely high duty ratio to achieve high voltage gain, thereby resulting in severe reverse-recovery problems and increased device stress. However, the use of the tapped-coupled-inductor boost converter with a high turns ratio allows the attainment of high step-up ratios with a low duty ratio.

As shown in Fig. 5, a voltage gain of 10 is achieved with a duty ratio of 0.9 by the conventional boost converter. However, the same voltage gain can be achieved by the tapped-coupled boost converter with a duty ratio of only 0.56 and turns ratio of 6 and a low duty ratio of 0.46 and turns ratio of 10 . The relationship between voltage gain and duty ratio becomes linear as $n$ approaches infinity. However, selecting the number of turns should be a trade-off. Considering that a high boost ratio is achieved with an extremely high turns ratio, (1) losses in winding $N_{2}$ increase and result in low efficiency; (2) a small input variation leads to a large output variation, which makes control difficult; (3) the value of inductor $L_{2}$ is large, leading to slow dynamic response; and (4) the input current peak-to-peak ripple increases.

Coupling coefficient $k$ is a measure of magnetic coupling between two coils. $k$ lies within the range $0 \leq k \leq 1$. When the two windings are tightly coupled such that all the flux linking the primary winding also links the secondary winding, no leakage inductance occurs and $k=1$. This situation is ideal because winding two coils in such a way that they share precisely the same magnetic flux is impossible.

The value of leakage inductance $L_{\ell}$ is defined by the expression $L_{\ell}=L_{1} \times(1-k)$. The energy stored in $L_{\ell}$ during $0<\mathrm{t}<\mathrm{DT}_{\mathrm{sw}}$ is

$$
\mathrm{W}_{\ell}=\left(\frac{1}{2}\right) \times\left(L_{\ell}\right) \times\left(I_{L 1}\right)^{2} .
$$

However, a high value of $k$ (approximately 0.98 ) can be obtained by tight coupling of the windings, thereby reducing the leakage inductances in the tapped-coupled inductors. $k$ can be determined by measuring individual winding self-inductances $L_{1}$ and $L_{2}$ with each of the other open-circuit windings. The two windings are then connected in a series, and the combined inductance is measured in series-aiding connection $L_{\text {aid }}$ and series-opposing connection $L_{\text {opp }}$ [15].

$$
k \text { is then obtained as } k=\frac{L_{a \dot{ }}-L_{o p p}}{4 \sqrt{L_{1} L_{2}}} \text {. }
$$

\section{WAVEFORM ANALYSIS}

The key waveforms of a single-phase tapped-coupled-inductor boost converter are shown in Fig. 6. The shape of the current that passes through the tapped-coupled-inductor boost converter is significantly different from that in a conventional boost converter because of the tapped-coupled inductor. When the active switch is conducting, the current flowing through the first inductor winding $\left(\mathrm{N}_{1}\right)$ ramps up linearly from its initial value until the switch goes off. No current flows through the second winding $\left(\mathrm{N}_{2}\right)$ during this interval because the diode is reverse biased. During the switching transitions, the flux through the core cannot change instantaneously; thus, the current flowing through $\mathrm{N}_{1}$ steps down immediately when the switch is turned off. When the active switch stops conducting, the diode becomes forward biased. The same current flows through both sections of the tapped inductor.

The waveforms in Fig. 6 are utilized to derive expressions for input current peak-to-peak ripple, RMS current, RMS ripple, and output capacitor RMS current. The expressions are derived to determine the input and output performance of the single-phase tapped-coupled inductor boost converter. The expressions for the average and nominal value of the output side inductor are obtained as

$$
\begin{gathered}
I_{L 2, \text { ave }}=I_{o, \text { ave }}=I_{L 2, \text { nom }}(1-D) \\
I_{L 2, \text { nom }}=\frac{I_{o, \text { ave }}}{(1-D)} .
\end{gathered}
$$

If the operating conditions are ideal, then

$$
P_{\boldsymbol{n}}=P_{o} \Rightarrow V_{\dot{\boldsymbol{n}}, \text { ave }} I_{\boldsymbol{n}, \text { ave }}=V_{o, \text { ave }} I_{o, \text { ave }}
$$

From Equations (21), (25), and (26), the expression for average input current is obtained as 


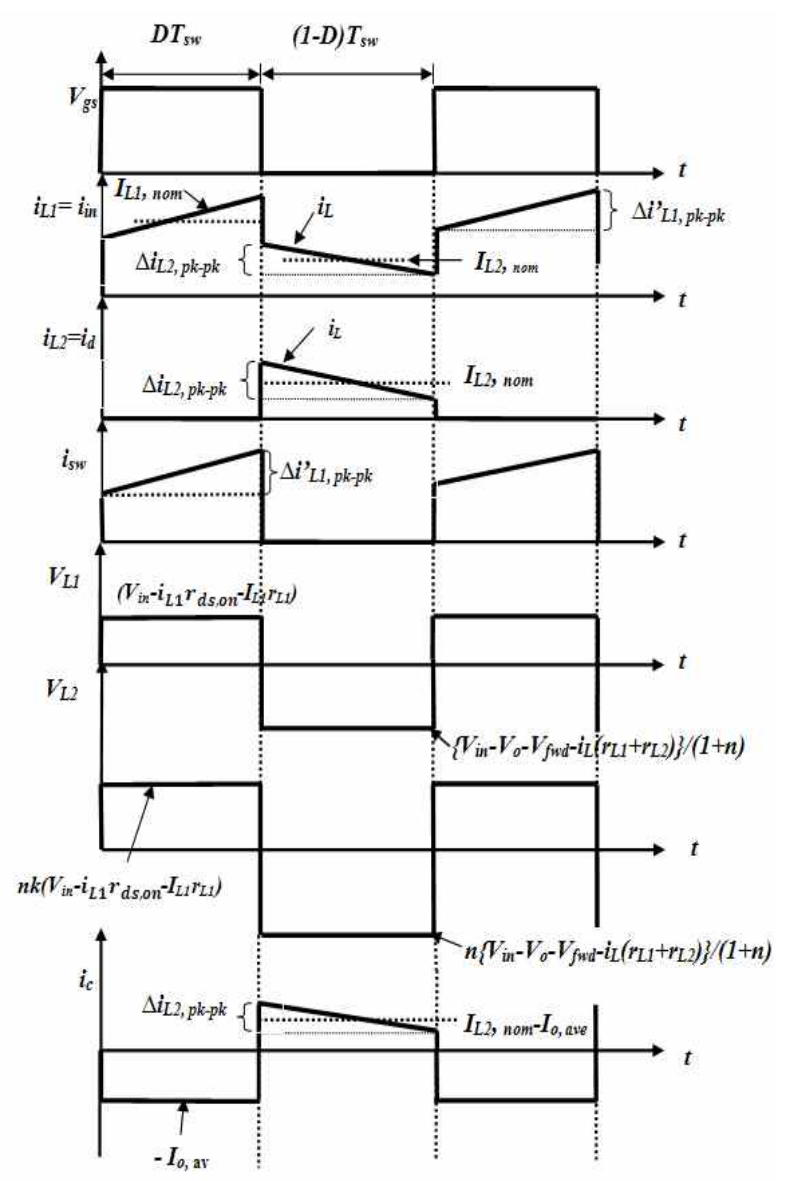

Fig. 6. Key waveforms for the single-phase tapped-coupled-inductor boost converter.

$$
I_{\text {n, ave }}=I_{L 1, \text { ave }}=I_{L 1, \text { nom }} D+I_{L 2, n o m}(1-D)=\frac{1+n k D}{1-D} I_{o, \text { ave }} .
$$

Substituting Equation (24) into (27) yields

$$
I_{L 1, n o m} D=\left(\frac{1+n k D}{1-D}-1\right) I_{o, \text { ave }}=\left(\frac{D+n k D}{1-D}\right) I_{o, \text { ave }} .
$$

The expressions for $I_{L 1, \text { nom }}$ and $I_{i n, \text { ave }}$ are obtained based on $I_{L 2 \text {, }}$ nom from Equation (28).

$$
\begin{gathered}
I_{L 1, n o m}=\left(\frac{1+n k}{1-D}\right) I_{o, a v e}=(1+n k) I_{L 2, n o m} . \\
I_{\text {in ,ave }}=I_{L 1, \text { ave }}=(1+n k) I_{L 2, n o m} D+I_{L 2, n o m}(1-D)= \\
(n k D+1) I_{L 2, n o m} .
\end{gathered}
$$

From Equations (2) and (14),

$$
\begin{gathered}
\Delta i_{L 1, p k-p k}^{\prime}=\frac{\left(V_{\dot{i n}}-i_{L 1} r_{d s, o n}-i_{L 1} r_{L 1}\right) D T_{S W}}{L_{1}} \\
\Delta i_{L 2, p k-p k}=\frac{n\left(V_{\dot{m}}-V_{o}-V_{f w} d^{-} i_{L}\left(r_{L 1}+r_{L 2}\right)\right)(1-D) T_{S W}}{(n+1) L_{2}} .
\end{gathered}
$$

The expression for input RMS current in the single-phase tapped-coupled-inductor boost converter is then obtained with reference to Fig. 6 and Equations (25), (29), (31), and
(32).

$$
\begin{aligned}
& I_{L 1, r m s}=I_{\text {i }, r m s}= \\
& \sqrt{\left\{\begin{array}{c}
\left(\left(\frac{1+n k}{1-D}\right) I_{o, a v e}\right)^{2} D\left[1+\frac{1}{3}\left(\frac{\Delta i^{\prime}{ }_{L 1, p k-p k}}{2\left(\frac{1+n k}{1-D}\right) I_{o, a v e}}\right)^{2}\right]+ \\
\left(\frac{I_{o, a v e}}{(1-D)}\right)^{2}(1-D)\left[1+\frac{1}{3}\left(\frac{\Delta i_{L 2, p k-p k}}{2\left(\frac{I_{o, a v e}}{(1-D)}\right)}\right)^{2}\right]
\end{array}\right\}}
\end{aligned}
$$

Equation (33) shows that input RMS current is dependent on turns ratio, coupling coefficient, duty ratio, and load current and that it approaches infinity as the duty ratio approaches unity. For a given duty ratio, a high value of turns ratio and coupling coefficient results in a high value of input RMS current.

Input RMS current ripple can then be obtained with reference to Fig. 6 and Equations (27) and (33).

$I_{o, \text { ave }} \sqrt{\left\{\begin{array}{c}D\left(\frac{1+n k}{1-D}\right)^{2}\left[1+\frac{1}{3}\left(\frac{\Delta i^{\prime} L 1, p k-p k}{2\left(\frac{1+n k}{1-D}\right) I_{o, a v e}}\right)^{2}\right]+ \\ \frac{1}{(1-D)}\left[1+\frac{1}{3}\left(\frac{\Delta i_{L 2, p k-p k}}{2\left(\frac{I_{o, a v e}}{(1-D)}\right)}\right)^{2}\right]-\left(\frac{1+n k D}{1-D}\right)^{2}\end{array}\right.}$

Equation (34) indicates that the input RMS current ripple expression approaches infinity as the duty ratio approaches unity. Input ripple depends on turns ratio, coupling coefficient, duty ratio, and load current. High values of duty ratio, turns ratio, coupling coefficient, and load current result in high input ripple current.

Based on Fig. 6 and Equations (25), (29), (31), and (32), the expression for peak-to-peak input current ripple is obtained as

$$
\begin{aligned}
& i_{\dot{\boldsymbol{n}}, p k-p k}=\left[\left(\frac{n k}{1-D}\right) I_{o, a v e}+\left(\frac{\left(V_{\dot{\boldsymbol{m}}}-i_{L 1} r_{d s, o n}-i_{L 1} r_{L 1}\right) D T_{S W}}{2 L_{1}}\right)\right]+ \\
& \left(\frac{n\left(V_{\dot{\boldsymbol{n}}}-V_{o}-V_{f w d}-i_{L}\left(r_{L 1}+r_{L 2}\right)\right)(1-D) T_{s w}}{2(n+1) L_{2}}\right)
\end{aligned}
$$

The input peak-to-peak current expression in Equation (35) increases with the increase in turns ratio, coupling coefficient, inductor value, duty ratio, and load current. The expression approaches infinity as duty ratio approaches unity.

Based on Fig. 6 and Equation (25), the expression for capacitor RMS current is obtained as

$I_{c, r m s}=\sqrt{\left\{\begin{array}{c}\left(I_{o, a v e}\right)^{2} D+\left(\frac{D I_{o, a v e}}{(1-D)}\right)^{2}(1-D) \times \\ {\left[1+\frac{1}{3}\left(\frac{\Delta i_{L 2, p k-p k}}{2\left(\frac{D I_{o, a v e}}{(1-D)}\right)}\right)^{2}\right]}\end{array}\right\}}$

Equation (36) shows that capacitor RMS current is almost independent of turns ratio and coupling coefficient for a fixed load current except for the term $\Delta i_{L 2, p k-p k}$.

\section{PERFORMANCE ANALYSIS}




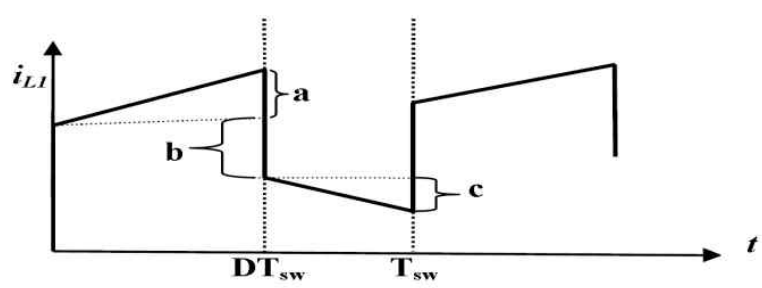

(a) Continuous conduction mode.

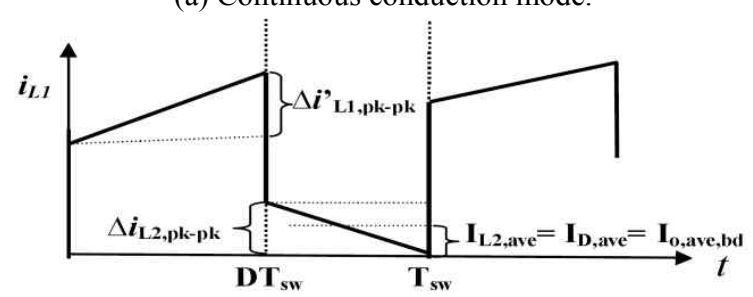

(b) Operation at the boundary between continuous and discontinuous conduction modes.

Fig. 7. Inductor $i_{\mathrm{L} 1}$ current waveform.

The performance of the single-phase tapped-coupled-inductor boost converter was evaluated by designing and simulating a converter with the following specifications: $V_{\text {in }}=40 \mathrm{~V}, V_{\text {out }}=400 \mathrm{~V}, P_{\mathrm{o}}=1,000 \mathrm{~W}, f_{s w}=$ $100 \mathrm{kHz}$, output voltage ripple is $1.25 \%$ of the capacitor voltage, $k=0.98, n=10, r_{\mathrm{L} 1}=2.23 \mathrm{~m} \Omega, r_{\mathrm{L} 2}=240 \mathrm{~m} \Omega$, and $\mathrm{R}_{\mathrm{ds}(\mathrm{on})}=49 \mathrm{~m} \Omega$. Equation (18) was utilized to calculate turns ratio $n$ to achieve the required voltage boost ratio of approximately 10 times at a low duty ratio of less than 0.5 . A turns ratio of 10 was therefore utilized in the design. An output capacitor with a value of $2.5 \mu \mathrm{F}$ was employed.

\section{A. Tapped-Coupled-Inductor Sizing}

The current that passes through the first portion of the tapped-coupled-inductor is shown in Fig. 7(a). The current variation marked "a" occurs when the switch is conducting. This variation depends on the size of the first inductor. The current variation marked " $b$ " varies with turns ratio and load. The current variation marked "c" occurs when the switch is off and depends on the size of the two coupled inductors in a series. For the tapped-coupled-inductor boost converter, the size of the inductor alone cannot decrease the inductor current ripple substantially because of the nature of the converter's waveform.

Sizing of the inductor was therefore based on both input current ripple minimization and the conditions for the discontinuous inductor current as shown in Fig. 7(b).

Fig. 7(b) shows that when operating at the boundary between continuous and discontinuous conduction, the average output current of the tapped-coupled-inductor boost converter is equal to half the peak-to-peak current variation denoted as "c." For operating conditions with a given set of values, namely, $\mathrm{T}_{\mathrm{sw}}, \mathrm{V}_{\mathrm{in}}, \mathrm{V}_{\mathrm{o}}, \mathrm{L}, n$, and $\mathrm{D}$, if the average output current is less than $0.5 \mathrm{c}$, then the inductor current becomes discontinuous. Thus, the inductors were sized to ensure that inductor current does not become discontinuous for as long as the output power is greater than the predetermined value.

$$
I_{o, a v e, b d}=\frac{1}{2} \Delta i_{\mathrm{L} 2, p k-p k}=\frac{1}{2}\left[\frac{n\left(V_{\dot{\boldsymbol{n}}}-V_{o}\right)(1-D) T_{S w}}{(1+n) L_{2}}\right]
$$

For $\mathrm{V}_{\text {in }}=40 \mathrm{~V}, \mathrm{~V}_{\mathrm{o}}=400 \mathrm{~V}, n=10, \mathrm{D}=0.5, \mathrm{f}_{\mathrm{sw}}=100 \mathrm{kHz}$, and $\mathrm{P}_{\mathrm{o}}=1 \mathrm{~kW}$,

$$
I_{o, a v e, b d}=\left[\frac{8.812 \times 10^{-4}}{L_{2}}\right] .
$$

Selecting a current variation, $\Delta i_{\mathrm{L} 2, \mathrm{pk}-\mathrm{pk}}$, of $15 \%$ of $\mathrm{I}_{\mathrm{o}, \text { ave }}$ ensures continuous conduction mode operation for as long as the load is greater than $7.5 \%$ of the rated value.

$$
\begin{gathered}
\Delta i_{\mathrm{L} 2, p k-p k}=15 \% \times 2.5 \mathrm{~A}=0.375 \mathrm{~A} \approx 0.4 \\
I_{o, a v e, b d}=\left[\frac{0.4}{2}\right]=0.2 \mathrm{~A}
\end{gathered}
$$

The output power at the boundary is $0.2 \mathrm{~A} \times 400 \mathrm{~V}=$ $80 \mathrm{~W}$. Operation below this power level leads to a discontinuous inductor current.

$$
\begin{aligned}
L_{2}=\left[\frac{8.812 \times 10^{-4}}{0.2}\right] & \approx 4 m \mathrm{H} \\
& \frac{L_{2}}{L_{1}}=\left(\frac{N 2}{N 1}\right)^{2}=n^{2}
\end{aligned}
$$

For $n=10, \mathrm{~L}_{1}=\frac{4 m \mathrm{H}}{10^{2}}=40 \mu \mathrm{H}$.

The mutual inductance is $M=k \times \sqrt{L_{1} \times L_{2}}$, where $k$ is the coupling coefficient. For $k=0.98, M=392 \mu \mathrm{H}$.

\section{B. Active Switch Selection}

The active switch is sized by considering its blocking voltage when it is not conducting. Fig. 4 shows that when the switch is not conducting,

$$
V_{d s}=V_{\text {in }}-V_{\mathrm{L} 1} \text {. }
$$

Based on Equation (14),

$$
V_{d s}=V_{\dot{\boldsymbol{n}}}-\frac{\left\{V_{\boldsymbol{n}}-V_{o}-V_{f w d}-i_{L}\left(r_{L 1}+r_{L 2}\right)\right\}(1+n k)}{1+2 n k+n^{2}} .
$$

The voltage blocked by the switch when it is not conducting, ignoring the spike due to the leakage inductance of the coupled inductors, is

$$
V_{d s}=\frac{V_{\dot{m}}\left(n k+n^{2}\right)+\left(V_{o}+V_{f w} d^{+i_{L}}\left(r_{L 1}+r_{L 2}\right)\right)(1+n k)}{1+2 n k+n^{2}} .
$$

Based on Fig. 6, the expression for switch RMS current is obtained as

$$
I_{s, r m s}=\sqrt{\left\{\left(\left(\frac{1+n k}{1-D}\right) I_{o, a v e}\right)^{2} D\left[1+\frac{1}{3}\left(\frac{\Delta i^{\prime}{ }_{L 1, p k-p k}}{2\left(\frac{1+n k}{1-D}\right) I_{o, a v e}}\right)^{2}\right]\right\}} .
$$


TABLE I

Performance Parameters in A Single-Phase TAPPED-COUPLED-INDUCTOR BOOST CONVERTER

\begin{tabular}{|c|c|c|c|c|c|}
\hline & D & $\begin{array}{c}\mathbf{I}_{\text {in,rms }} \\
(A)\end{array}$ & $\begin{array}{c}\mathbf{I}_{\text {in,rms ripple }} \\
(\mathrm{A})\end{array}$ & $\begin{array}{c}\mathbf{I}_{\text {in,pk-pk }} \\
(\mathrm{A})\end{array}$ & $\begin{array}{c}\mathbf{I}_{\text {c,rms }} \\
(\mathrm{A})\end{array}$ \\
\hline Simulation & $\mathbf{0 . 4 9 4}$ & 39.3 & 25.05 & 53.1 & 2.49 \\
\hline Analysis & $\mathbf{0 . 4 9 4}$ & 37.67 & 24.21 & 51.1 & 2.47 \\
\hline
\end{tabular}

With reference to Fig. 6 and Equations (29) and (31), the expression for the peak switch current is

$i_{s, p k}=\left(\frac{1+n k}{1-D}\right) I_{o, a v e}+\frac{1}{2}\left(\frac{\left(V_{\dot{n}}-i_{L 1} r_{d s, o n}-i_{L 1} r_{L 1}\right) D T_{S W}}{L_{1}}\right)$.

Equation (45) indicates that an increase in the coupled inductor's turns ratio $n$ translates into a nonlinear decrease in $\mathrm{V}_{\mathrm{ds}}$. For a given voltage ratio, an increase in $n$ results in a non-linear decrease in duty ratio $D$. From Equations (46) and (47), an increase in $n$ results in a linear increase in both switch RMS and peak current despite the reduction in $D$.

This occurrence would lead to an increase in switching and conduction losses in the active switch. Thus, a compromise should be made between turns ratio and duty ratio to ensure that minimal switching losses are incurred.

\section{Output diode selection}

Diode blocking voltage $V_{d}$ was determined to size the output diode by considering the voltage across the diode when the active switch is conducting. Based on Fig. 3 and Equation (3),

$$
V_{D}=-\left(i_{d s} r_{d s(\text { on })}+n k\left(V_{\text {in }}-i_{L 1} r_{d s, \text { on }}-i_{L 1} r_{L 1}\right)+V_{\text {out }}\right) \text {. }
$$

Equation (48) shows that the diode blocking voltage requirement increases as both $n$ and $k$ increase. Diode RMS current is obtained with reference to Fig. 6 as

$$
I_{D, r m s}=\sqrt{\left\{\left(\frac{I_{o, a v e}}{(1-D)}\right)^{2}(1-D)\left[1+\frac{1}{3}\left(\frac{\Delta i_{L 2, p k-p k}}{2\left(\frac{I_{o, a v e}}{(1-D)}\right)}\right)^{2}\right]\right\}}
$$

Equation (49) indicates that diode RMS current increases non-linearly with duty ratio and is almost independent of both $n$ and $k$ for a fixed load current.

Based on Fig. 6 and Equations (25) and (32), the expression for diode peak current is

$$
i_{D, p k}=\frac{I_{o, a v e}}{(1-D)}+\frac{1}{2}\left(\frac{n\left(V_{\boldsymbol{n}}-V_{O}-V_{f w} d^{-} i_{L}\left(r_{L 1}+r_{L 2}\right)\right)(1-D) T_{S W}}{(n+1) L_{2}}\right) .
$$

Diode peak current is almost independent of both $n$ and $k$ for a fixed load current as shown in Equation (50).

\section{Simulation results}

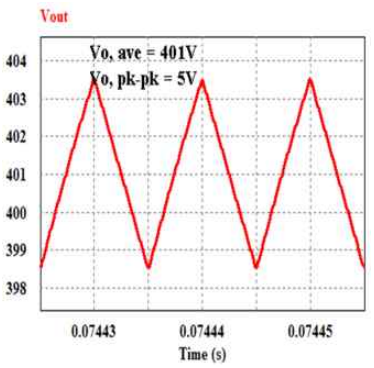

(a)

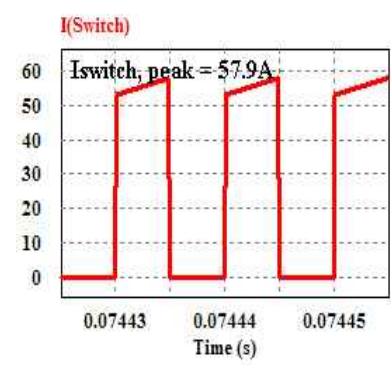

(b)
Fig. 9. Simulated converter waveforms. (a) Output voltage and (b) switch current.

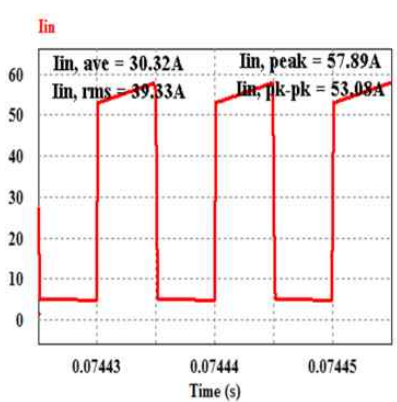

(a)

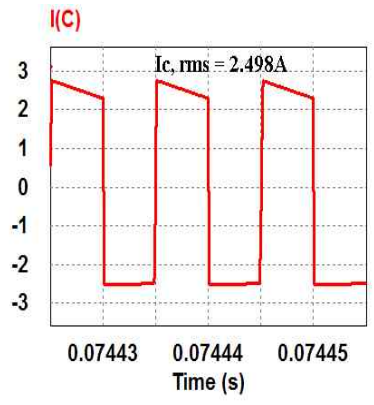

(b)
Fig. 10. Simulated converter waveforms. (a) Input current and (b) capacitor current.

Simulations of a non-ideal single-phase tapped-coupled-inductor boost converter with the aforementioned specifications were conducted. The characteristics were plotted and compared with those from the derived analytical expressions. The MOSFET and diode models utilized in the simulations are IXFT69N30P and the RHRP15120, respectively. An RCD snubber consisting of a $200 \Omega$ resistor, a $2.2 \mu \mathrm{F} 250 \mathrm{~V}$ capacitor, and an RHRP 15120 diode was employed to suppress the voltage spike across the MOSFET.

The performance parameters obtained from the simulations are summarized in Table 1.

Figs. 9(a) and (b) show the simulated output voltage and switch current waveforms. Figs. 10(a) and (b) present the simulated input and capacitor current waveforms. The values in Table 1 and the output voltage waveforms in Fig. 9(a) confirm that the boost converter with tapped-coupled inductors achieves a high voltage boost ratio without an extreme duty ratio.

A high boost ratio of approximately 10 times was achieved at a duty ratio of 0.494 . The input, output, and capacitor current waveforms demonstrate the converter's input-side and output-side performance. The values of input RMS, average, and RMS current ripple are shown in Table 1. The values obtained through the simulations are in good agreement with those obtained from Equations (27), (33), and (34). Despite its high voltage boost capabilities, the converter is limited by 


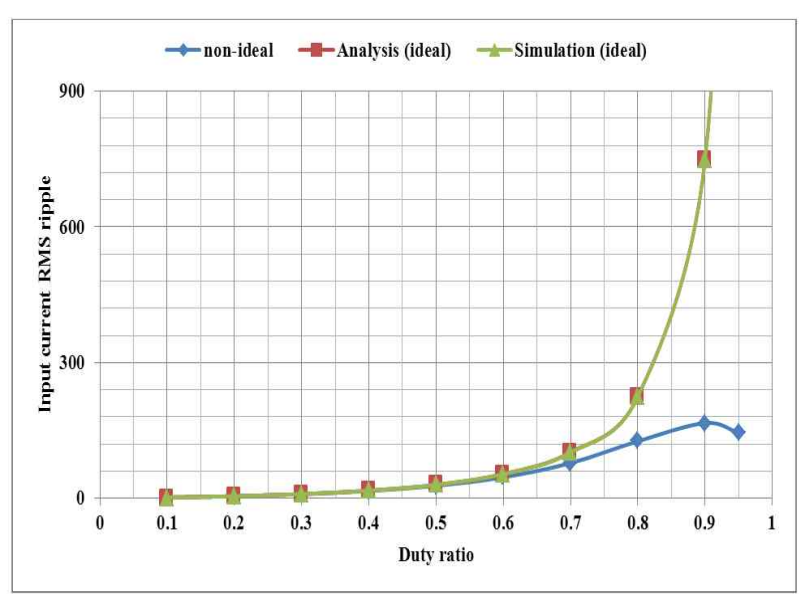

Fig. 11. Input RMS current ripple against duty ratio.

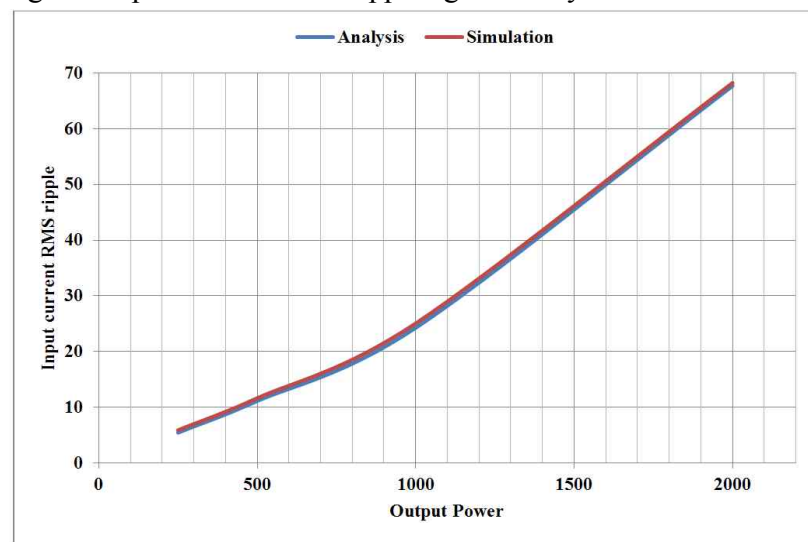

Fig. 12. Input RMS current ripple against power characteristics.

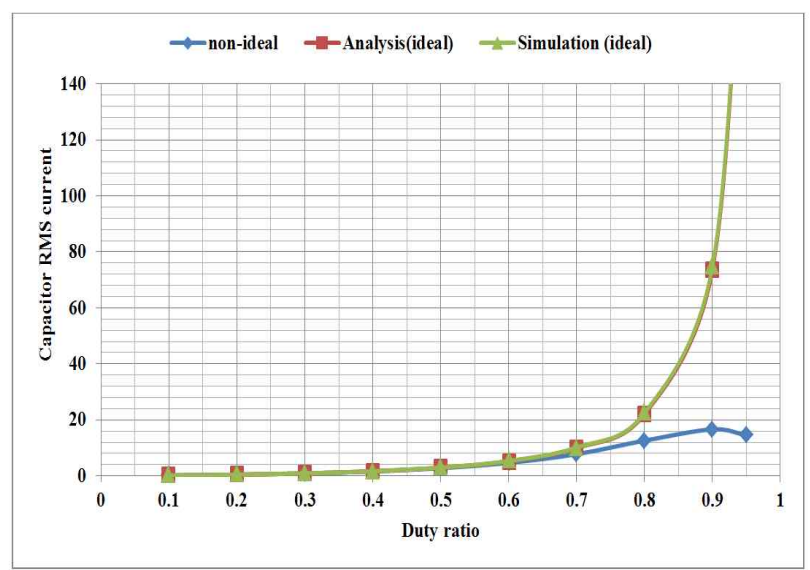

Fig. 13. Capacitor RMS current against duty ratio.

its high peak-to-peak input current ripple. This limitation can be attributed to the dependence of input current on inductor size, turns ratio, and loading. When this converter is utilized, a trade-off has to be made to achieve a high boost ratio at an acceptable input current ripple depending on the application.

The output capacitor waveform with an RMS value of 2.5 A for the simulated specifications is presented in Fig. 10(b). This RMS value is in accordance with that from the analytical expression derived through Equation (36).

Fig. 11 shows the curves for input RMS current ripple variation with a duty ratio obtained from the simulation of a non-ideal converter, an ideal converter, and the analytical expression in Equation (34). The curves were obtained at variable output power and voltage with a turns ratio of 10 between the tapped-coupled inductors. As the duty ratio increases, output voltage and load current also increase.

Fig. 11 indicates that the derived analytical expression and simulation are in good agreement. Input current ripple increases non-linearly with an increase in the duty ratio. This occurrence should be considered when selecting the values of $n$ and $D$. The effects of the non-ideal characteristics of the components on input current ripple are also evident.

Fig. 12 shows the variation in input RMS current ripple with load at a fixed duty ratio. Output load varies with variations in load current and output power. A curve was obtained with simulated data, and another curve was obtained by calculating Equation (34). Input current ripple increases with load. The non-linearity in the curve in Fig. 12 is due to the effects of the non-ideal components included in the simulation and analytical expression. This finding suggests that aside from the duty and turns ratio, the operating power of the converter should also be considered to ensure high performance.

Fig. 13 shows the variation in output capacitor RMS current with duty ratio. Non-ideal and ideal converter simulations and characteristics were compared via Equation (36).

The good agreement between the simulations and the derived expression is evident. The effects of the non-ideal characteristics of the converter components on capacitor current are also evident. Fig. 13 shows that operating the converter at a low duty ratio generates a low capacitor current ripple. A small capacitor can thus be utilized when the operation is maintained at a low duty ratio.

Fig. 14 presents the efficiency-power characteristics of the boost converter with tapped-coupled inductors. Output load changed at a constant output voltage, thereby changing the output power and duty ratio while maintaining the same boost ratio. The characteristics were obtained from the simulated converter, and the MOSFET switching losses were ignored. Fig. 14 shows that at extremely low output power, efficiency is low and increases with load, attains the maximum value, and then decreases as the load is further increased. The decrease in efficiency at high power levels is due to the increase in the peak and RMS values of currents in the converters, resulting in high copper, switching, and conduction losses.

\section{EXPERIMENTAL VERIFICATION}

A prototype of the simulated single-phase tapped-coupled-inductor boost converter was built to verify 


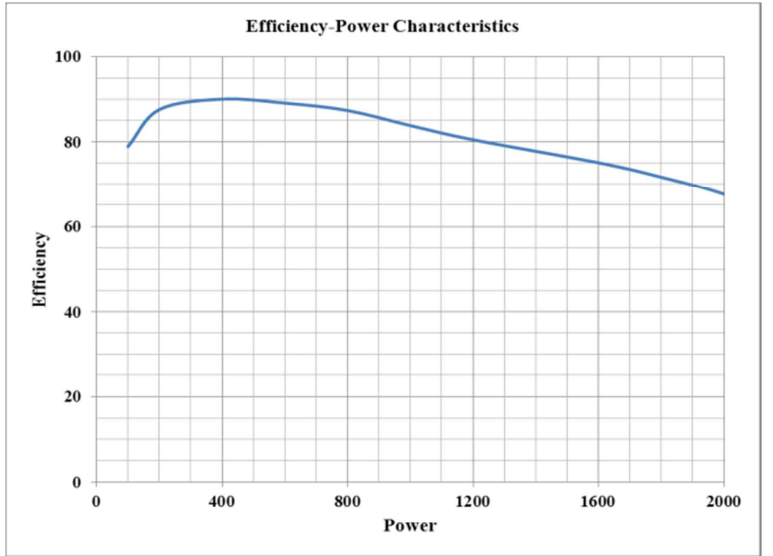

Fig. 14. Variation in efficiency with power.

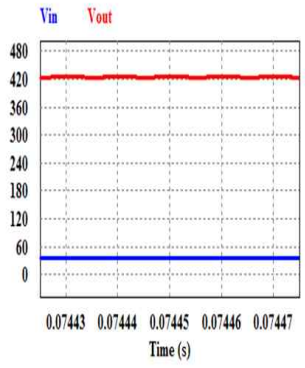

(a)

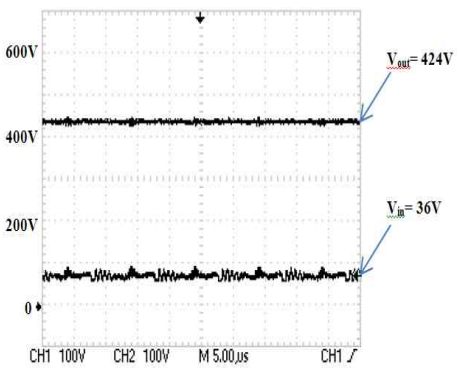

(b)

Fig. 15. (a) Simulated and (b) experimental input and output voltages.

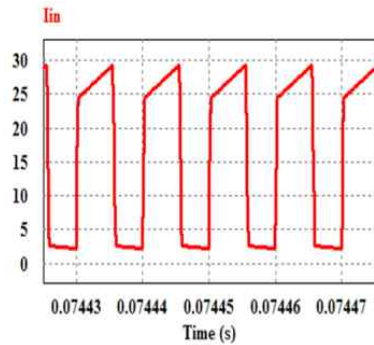

(a) Simulated.

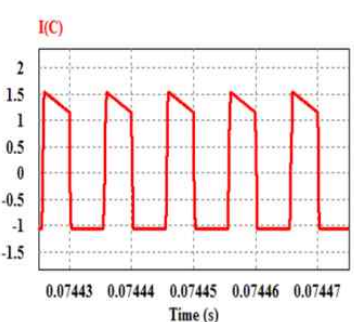

(c) Simulated. (d) experimental output capacitor current. the theoretical analysis and simulation results in the previous sections. The prototype was designed for rated power of $1,000 \mathrm{~W}$ but was tested at a low power of $450 \mathrm{~W}$ because of power supply constraints in the laboratory. The switch utilized was an IXFT 69N30P MOSFET with a blocking voltage of $300 \mathrm{~V}$, drain current of $69 \mathrm{~A}$ at a junction
TABLE II

COMPARISON OF EXPERIMENTAL, SIMULATION, AND ANALYTICAL RESULTS

\begin{tabular}{|c|c|c|c|}
\hline & $\mathbf{I}_{\mathbf{i n}, \mathbf{r m s}}$ & $\mathbf{I}_{\mathbf{i n}, \mathbf{p k} \mathbf{p k}}$ & $\mathbf{I}_{\mathbf{c}, \mathbf{r m s}}$ \\
\hline Experimental & $19 \mathrm{~A}$ & $21 \mathrm{~A}$ & $0.95 \mathrm{~A}$ \\
\hline Simulation & $19.5 \mathrm{~A}$ & $22.3 \mathrm{~A}$ & $0.97 \mathrm{~A}$ \\
\hline Analysis & $19.1 \mathrm{~A}$ & $26.8 \mathrm{~A}$ & $0.96 \mathrm{~A}$ \\
\hline
\end{tabular}

temperature of $25^{\circ} \mathrm{C}$, and $\mathrm{Rds}$ (on) of $49 \mathrm{~m} \Omega$. The diode was a $15 \mathrm{~A}, 1200 \mathrm{~V}$ RHRP 15120 hyperfast diode. An RCD snubber consisting of a $200 \Omega$ resistor, a $2.2 \mu \mathrm{F}, 250 \mathrm{~V}$ capacitor, and an RHRP 15120 diode was employed to suppress the voltage spike across the MOSFET by dissipating the leakage energy through the snubber resistor.

A coupling coefficient of 0.99 was obtained. The coupled-inductor series resistances are $r_{\mathrm{L} 1}=2.23 \mathrm{~m} \Omega$ and $r_{\mathrm{L} 2}=240 \mathrm{~m} \Omega$. The laboratory prototype was supplied a DC voltage of $36 \mathrm{~V}$ and tested at a duty ratio of 0.55 . Figs. 15 and 16 show the experimental and simulated waveforms of the tapped-coupled-inductor converter.

Figs. 15 and 16 reveal the similarity between the simulation and experimental waveforms. Fig. 15 shows the experimental input and output voltage waveforms in the single-phase tapped-coupled-inductor boost converter.

An output voltage of $424 \mathrm{~V}$ is achieved with an input voltage of $36 \mathrm{~V}$ at a duty ratio of 0.55 . This result translates into a voltage boost ratio of approximately 11.8 times, thereby confirming the high boost capabilities of tapped-coupled inductor boost converters without an extreme duty ratio. Fig. 16 shows the input and capacitor currents of the converter. The experimental, simulated, and analytical results as well as the capacitor current values are compared in Table 2. Good agreement was observed among the practical, simulation, and analytical results. This observation verifies the derived expressions.

Table 3 presents the calculated losses in the experimental converter. RCD snubber loss accounts for $61 \%$ of the total converter loss, thereby reducing the conversion efficiency of the converter with values of $77.6 \%, 77.9 \%$, and $78 \%$ achieved at $200 \mathrm{~W}, 305 \mathrm{~W}$, and $450 \mathrm{~W}$, respectively. However, active-clamp snubbers that do not induce losses can be utilized to improve conversion efficiency at the expense of topological complexity. These snubbers recycle leakage energy.

\section{CONCLUSIONS}

This study examined the operation, characterization, and design expressions of a single-phase tapped-coupled-inductor boost DC-DC converter in CCM mode. A voltage transfer function that considers non-ideal characteristics was derived. The factors that affect boost ratio, including duty ratio, turns ratio, and coupling coefficient, were identified. Analytical 
TABLE III

Calculated Converter Losses At Different Power Levels

\begin{tabular}{|c|l|l|l|l|l|l|c|}
\hline $\begin{array}{l}\text { Output } \\
\text { power }\end{array}$ & $\begin{array}{l}\text { Copper } \\
\text { loss }\end{array}$ & $\begin{array}{l}\text { Switch } \\
\text { conduction } \\
\text { loss }\end{array}$ & $\begin{array}{l}\text { Switching } \\
\text { loss }\end{array}$ & $\begin{array}{l}\text { Snubber } \\
\text { loss }\end{array}$ & $\begin{array}{l}\text { Diode } \\
\text { conduction } \\
\text { loss }\end{array}$ & $\begin{array}{l}\text { Total } \\
\text { loss }\end{array}$ & Efficiency \\
\hline $200 \mathrm{~W}$ & $0.83 \mathrm{~W}$ & $8.43 \mathrm{~W}$ & $7.56 \mathrm{~W}$ & $27.1 \mathrm{~W}$ & $0.8 \mathrm{~W}$ & $44.7 \mathrm{~W}$ & $77.6 \%$ \\
\hline $305 \mathrm{~W}$ & $1.19 \mathrm{~W}$ & $12.76 \mathrm{~W}$ & $11.52 \mathrm{~W}$ & $41.04 \mathrm{~W}$ & $0.8 \mathrm{~W}$ & $67.31 \mathrm{~W}$ & $77.9 \%$ \\
\hline $150 \mathrm{~W}$ & $1.67 \mathrm{~W}$ & $19 \mathrm{~W}$ & $16.94 \mathrm{~W}$ & $60.5 \mathrm{~W}$ & $0.97 \mathrm{~W}$ & $99.1 \mathrm{~W}$ & $78 \%$ \\
\hline
\end{tabular}

expressions for average, RMS, and ripple input current as well as the output capacitor RMS current were derived, and their dependence on turns ratio, coupling coefficient, duty ratio, and load current was investigated. These derived expressions are useful in designing the single-phase tapped-coupled-inductor boost converters. A practical and systematic approach for sizing the tapped-coupled-inductor boost converter was also presented. Results show that considering the size of the inductor alone cannot substantially decrease inductor current ripple because of the nature of the current waveform, which is unlike that of a conventional boost converter as suggested in literature.

The condition that produces discontinuous inductor current, which causes output inductor current to drop to zero during the diode conduction interval, was explained. The ripple in the inductor current was found to be dependent on inductor size, turns ratio, and load. The significant expressions required in sizing the active switch, output diode, and output capacitor were also derived, and the effects of turns ratio and coupling coefficient were explained.

Simulations and analytical expressions were utilized to demonstrate that input current ripple increases non-linearly with duty ratio and load. Efficiency increases initially with load, attains its maximum value, and then decreases non-linearly with a further increase in load. The use of this converter therefore requires trade-offs in duty ratio, turns ratio, and operating power. For a given voltage boost ratio, a low duty ratio results in a high turns ratio. This occurrence leads to increased peak-to-peak and RMS input current ripple.

\section{REFERENCES}

[1] C. Lee and Q. Zhao, "High-Efficiency, high step-up DC-DC converters," IEEE Trans. Power Electron., Vol. 18, No.1, pp.65-73, Jan. 2003.

[2] A. Emadi and S. S. Williamson. "Fuel cell vehicles: opportunities and challenges," IEEE Power Engineering Society General Meeting., Vol. 2, pp.1640-1645, Jun. 2004.

[3] K. C. Tseng and T. J. Liang, "Novel high-efficiency step-up converter," IEE Proc.-Electr. Power Appl., Vol. 151, No. 2, pp.182-190, Mar. 2004.

[4] D. A. Grant and Y. darroman, "Extending the tapped-inductor DC-to-DC converter family," Electronics letters, Vol. 37, No. 3, pp. 145-146, Feb. 2001.

[5] D. A. Grant and Y. darroman, "Watkins-Johnson converter completes tapped inductor converter matrix," Electronics letters, Vol. 39, No. 3, pp. 145-146, Feb. 2003.

[6] J. H. Park and B. H. Cho, "The zero voltage switching (ZVS) critical conduction mode (CRM) buck converter with tapped-inductor," IEEE Trans. Power Electron., Vol. 20, No. 4, pp. 762-774, Jul. 2005.

[7] K. Yao, M. Yeh, M. Xu and F. C. Lee, "Tapped-Inductor Converter for High-Step-Down DC-DC Conversion," IEEE Trans. Power Electron., Vol. 20, No. 4, pp. 775-780, Jul. 2005.

[8] J. P. Fohringer and F. A. Himmelstoss, "Analysis of a boost converter with tapped inductor and reduced voltage stress across the buffer capacitor," IEEE Industrial Technology Conf., pp. 126-131, 2006.

[9] N. Vazquez, L. Estrada, C.Hernandez, and E. Rodriguez, "The tapped-inductor boost converter," IEEE International Symposium on Industrial Electronics, pp. 538-543, Jun. 2007.

[10] J. J. Lee and B. H. Cho, "A novel high step-up zero-current-switching tapped-inductor boost converter," In the $8^{\text {th }}$ International Conf. on Power Electron., pp.1869-1872, Jun. 2011.

[11] D. A. Grant, Y. Darroman, and S. James, "Synthesis of tapped-inductor switched-mode converters," IEEE Trans. Power Electron., Vol. 22, No. 5, pp. 1964-1969, Sep. 2007

[12] J. C. Yris, J. H. Calleja, A. C. Sanchez and L. H. Gonzalez, "Study of a family of buck-boost converter with tapped inductor for grid-connected photovoltaic systems," Electronics, Robotics and Automotive Mechanics Conference, pp. 581-585, Oct. 2010.

[13] H. F. A. Barberena, "Leveraging tapped-inductor architectures to increase power density of single and dual-polarity-output buck-boost converters," Applied Power Electronics Conference and Exposition, pp. 1447-1450, Mar. 2011.

[14] V. R. Tintu and M. George, "Tapped-inductor Technology Based DC-DC Converter," International Conference on Signal Processing, Communication, Computing and Network Technologies(ICSCCN), pp. 747-753, Sep. 2011.

[15] R. Balog, P. T. Krein, and D. C. Hamill, "Coupled inductors: A basic filter building block," in Proc., Electr. Mach. Coil Winders Assoc., 2000, pp. 271-278.

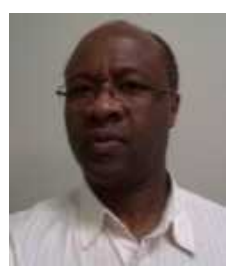

Michael Njoroge Gitau was born in Murang'a, Kenya. He received his B.Sc. and $\mathrm{Ph} . \mathrm{D}$. degrees in electrical engineering from the University of Nairobi, Kenya, and Loughborough University, UK, in 1984 and 1995, respectively. He worked for Kenya Railways Cooperation and the University of Nairobi before joining the faculty of 
engineering at the University of Pretoria. He is currently an associate professor in the Department of Electrical, Electronic, and Computer Engineering at the University of Pretoria. His interests include power electronics and electric drives.

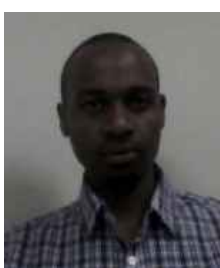

Fredrick Mukundi Mwaniki was born in Embu, Kenya. He received his B.Sc. and B.Eng. degrees in electrical engineering from the University of Nairobi, Kenya, and University of Pretoria, South Africa, in 2009 and 2011, respectively. $\mathrm{He}$ is currently pursuing a master's degree at the University of Pretoria, South Africa.

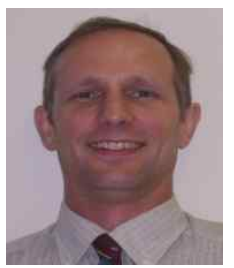

Ivan W. Hofsajer was born in Johannesburg, South Africa. He received his B.Ing. and D.Ing. degrees in electrical engineering from the former Rand Afrikaans University, Johannesburg, South Africa, in 1991 and 1998, respectively. He worked in the field of electromagnetic interference at the South African Atomic Energy Corporation before joining the faculty of Rand Afrikaans University. He is currently an associate professor in the School of Electrical and Information Engineering at University of Witwatersrand, Johannesburg. His interests include power electronics and electromagnetics. 